\title{
Indeks Pembangunan Berkelanjutan Lokal dan Sebaran Spasialnya di Kabupaten Mandailing Natal, Provinsi Sumatera Utara
}

\author{
Local Sustainable Development Index and Its Spatial Distribution \\ in Mandailing Natal Regency, North Sumatera Province
}

\author{
Elvina Nora Lubis ${ }^{{ }^{*}}$, Andrea Emma Pravitasari ${ }^{2,3}$ \& Dwi Putro Tejo Baskoro ${ }^{3}$ \\ ${ }^{1}$ Program Studi Ilmu Perencanaan Wilayah, Fakultas Pertanian, Institut Pertanian Bogor, Jalan Meranti \\ Kampus IPB Dramaga, Bogor, Jawa Barat, 16680, Indonesia; ${ }^{2}$ Pusat Pengkajian Perencanaan dan \\ Pengembangan Wilayah (P4W), Kampus IPB Baranangsiang, Jalan Raya Pajajaran, Bogor, Jawa Barat, \\ 16127, Indonesia; ${ }^{3}$ Departemen Ilmu Tanah dan Sumberdaya Lahan, Fakultas Pertanian, Institut Pertanian \\ Bogor, Jalan Meranti Kampus IPB Dramaga Bogor, Jawa Barat,16680, Indonesia; \\ *Penulis korespondensi.e-mail: himadaaplubis@apps.ipb.ac.id \\ (Diterima: 15 April 2021; Disetujui: 22 Juni 2021)
}

\begin{abstract}
The concept of sustainable development is very important to increase our quality of life. Measurement of development based on specific indicators is one of the approaches to describe sustainable development. At the local level, measuring sustainable development using specific indicators is still rare. Since each location has their own unique characteristics, measuring sustainability at the regional level could not always be applied locally. The availability of data at the village level strongly encourages the local measurement of sustainable development index. The economic, social, and environmental dimensions of Mandailing Natal Regency's development are still constrained. Using 21 variables that can reflect economic, social, and environmental aspects, this study aims to measure the sustainable development index at the local level. The Local Sustainable Development Index will be generated by analyzing these variables using the Factor Analysis (FA) method and Local Indicator of Spatial Autocorrelation (LISA) analysis. This index measurement is useful in considering the direction of location-based (spatial) development for decision makers at the local level and describe development sustainability. In general, IPBL economic value was in the medium category in 2011, and several villages in the low category were able to enhance their economic development sustainability in 2018. In the northwest, IPBL environment cluster type High-high (HH). In 2018, the percentage spatial distribution pattern of villages with the Low-low (LL) cluster type of IPBL economic and IPBL environment decreased. However, as can be seen from the spatial distribution pattern of IPBL social with cluster type LL, the percentage increased in 2018.
\end{abstract}

Keywords: factor analysis, LISA, Local Sustainable Development Index, spatial distribution

\begin{abstract}
ABSTRAK
Konsep pembangunan berkelanjutan penting untuk meningkatkan kualitas kehidupan. Pengukuran pembangunan berkelanjutan dengan indikator tertentu pada tingkat lokal masih jarang dilakukan. Pembangunan di Kabupaten Mandailing Natal masih terkendala, baik pada dimensi ekonomi, dimensi sosial, maupun pada dimensi lingkungan. Untuk mengetahui tingkat keberlanjutan pembangunan kabupaten ini diperlukan pengukuran Indeks Pembangunan Berkelanjutan di tingkat lokal. Pengukuran indeks pada tingkat lokal sangat diperlukan karena setiap lokasi memiliki karakteristik yang berbeda. Ketersediaan data pada tingkat desa sangat mendukung pengukuran indeks ini. Penelitian ini bertujuan untuk mengukur Indeks Pembangunan Berkelanjutan di tingkat
\end{abstract}


lokal, dengan menggunakan 21 variabel yang mewakili dimensi ekonomi, sosial, dan lingkungan. Variabel-variabel tersebut dianalisis dengan metode Faktor Analisis (FA) dan analisis LISA (Local Indicator of Spatial Autocorrelation) sehingga menghasilkan Indeks Pembangunan Berkelanjutan Lokal (IPBL). Pengukuran indeks ini bermanfaat sebagai bahan pertimbangan pengambilan kebijakan pada tingkat lokal dalam menentukan arah pembangunan berbasis lokasi (spasial) dan menggambarkan tingkat keberlanjutan pembangunan di Kabupaten Mandailing Natal. Pada umumnya nilai IPBL ekonomi pada wilayah ini berkategori berkategori sedang pada tahun 2011 dan beberapa desa berkategori rendah mampu meningkatkan keberlanjutan ekonominya pada tahun 2018. Sebaran pola spasial IPBL ekonomi dan IPBL sosial bertipe cluster High-high (HH) berada pada arah timur lokasi penelitian, dan sebaran IPBLlingkungan tipe cluster HH pada arah barat laut. Persentase desa dengan sebaran spasial IPBL ekonomi dan IPBL lingkungan tipe cluster Low-low (LL) berkurang pada tahun 2018. Namun keberlanjutan pembangunan sosialnya justru menurun, dapat diamati dari pola sebaran spasial IPBL sosial dengan tipe cluster LL persentasenya meningkat pada tahun 2018 .

Kata kunci: faktor analisis, Indeks Pembangunan Berkelanjutan Lokal, LISA, sebaran spasial.

\section{PENDAHULUAN}

Pengukuran pembangunan berkelanjutan membutuhkan indikator yang dapat memperjelas tentang objek, kuantitas dan waktu pembangunan yang akan dilakukan, indikator yang bisa memberikan persamaan persepsi dalam melaksanakan dan menilai kinerja pembangunan, dan yang dapat digunakan sebagai dasar untuk mengevaluasi dan menganalisis pelaksanaan pembangunan (Rustiadi et al., 2009). Indikator statistik yang memberikan informasi dan secara bersamaan dapat menyederhanakan proses analisis fenomena yang diteliti disebut dengan indeks (Saric et al., 2013).

Setianingtias et al. (2019), Rahma et al. (2019), Fauzi \& Oxtavianus (2014) mempertimbangkan aspek sosial, ekonomi dan lingkungan dalam pengukuran Indeks Pembangunan Berkelanjutan di tingkat regional. Indikator yang digunakan pada penelitian diatas hanya tersedia di tingkat provinsi atau kabupaten, dan untuk unit administrasi terkecil atau desa data indikator tersebut belum tersedia. Dengan unit analisis yang sama Pravitasari et al. (2018) mengukur indeks keberlanjutan dengan mempertimbangkan hubungan saling ketergantungan spasial pada skala regional. Fadli (2017) menyatakan bahwa sebagian besar kawasan di dunia memiliki karakteristik masing- masing, pengukuran keberlanjutan di tingkat desa tidak serta merta bisa menggunakan pengukuran keberlanjutan di tingkat regional.

Penentuan Indeks Pembangunan Berkelanjutan di tingkat kabupaten diperlukan sebagai bahan pertimbangan untuk menyusun strategi dalam pencapaian tujuan pembangunan. Karena indikator yang sama mempunyai pengaruh yang berbeda di masing masing wilayah. Sejalan dengan hal tersebut peneliti menganggap perlu melakukan pengukuran Indeks Pembangunan Berkelanjutan di tingkat lokal di Kabupaten Mandailing Natal dengan mempertimbangkan ketersediaan data yang ada di tingkat lokal dan dapat dipahami oleh pengambil keputusan.

Selang waktu 2010 sampai 2018 Angka Harapan Hidup (AHH) pada wilayah ini paling rendah jika dibandingkan dengan kabupaten lain di Provinsi Sumatera Utara, pertumbuhan ekonomi wilayah berpengaruh terhadap hal ini. AHH lazim dikaitkan dengan tingkat kemajuan suatu daerah. Daerah terbelakang umumnya memiliki AHH rendah (Bangun, 2019).

Pendapatan perkapita lebih rendah $46.00 \%$ dibandingkan dengan pendapatan perkapita Provinsi Sumatera Utara. Produk Domestik Regional Bruto (PDRB) sektor pertanian perikanan dan kehutanan merupakan porsi terbesar dari keseluruhan PDRB Kabupaten yaitu $43.63 \%$. Jumlah pengangguran 
sebesar $6.37 \%$ dan tingkat kemiskinan mencapai $9.11 \%$ (BPS, 2020).

Pada awal pembentukan kabupaten, sekitar $60 \%$ wilayahnya merupakan tutupan lahan hutan, dan menjadi 30\% pada tahun 2018 . Sihombing \& Sumaryono (2009) menyimpulkan telah terjadi penurunan luasan lahan hutan primer menjadi tutupan lahan non hutan yang dilakukan oleh pemegang izin baik secara legal maupun ilegal. Sampai tahun 2001 hutan primer yang berubah seluas 3,572.62 ha/tahun sementara itu izin untuk pemegang hak pengusahaan hutan (HPH) adalah 800.00 ha/tahun. Demikian halnya pada tahun 2004 telah terjadi penurunan luas hutan primer sebesar 1,523.92 ha/tahun. Selain untuk penggunaan lahan pertanian daerah hulu dan hilir DAS Batang Gadis digunakan sebagai area pertambangan. Daerah pinggiran sungai yang menjadi lokasi penambangan berubah menjadi lahan terbuka kemudian pelaku pertambangan membuang tanah bekas penambangan (tailing) ke aliran sungai. Pencemaran sungai juga terjadi akibat buangan bahan padat lainnya. Penduduk yang tinggal di sekitar aliran sungai, 70\% masih melakukan Buang Air Besar Sembarangan (BABs) (Bappeda, 2018). Atifah \& Harahap (2019) juga mengemukakan sungai Batang Gadis terindikasi terjadi pencemaran, peneliti tersebut menemukan ikan Garing yang mengalami edema dan nekrosis akibat akumulasi logam berat di Sungai Batang Gadis.

Tujuan penelitian ini adalah
mengidentifikasi indikator penciri Indeks
Pembangunan Berkelanjutan di tingkat lokal,
menghitung nilai Indeks Pembangunan
Berkelanjutan Lokal (IPBL) di Kabupaten
Mandailing Natal serta menganalisis pola spasial
sebaran nilai indeksnya.

\section{METODOLOGI}

Penelitian ini menggunakan data Potensi Desa (PODES) tahun 2011 dan 2018 yang dikeluarkan oleh Badan Pusat Statistik (BPS), dan interpretasi citra landsat dengan lembar citra Path /Row 128/59, dan 128/60. Landsat 5 TM diakuisisi tanggal 17 Mei 2008 dan tanggal 28 Januari 2011. Citra Landsat 8 diakuisisi tanggal 02 November 2014 dan tanggal 16 Juli 2018. Unit analisis penelitian ini adalah seluruh desa di Kabupaten Mandailing Natal, yang merupakan unit administrasi terkecil.

Kabupaten Mandailing Natal berada di Provinsi Sumatera Utara, terdiri dari 23 kecamatan 404 desa/kelurahan. Secara geografis terletak pada $0^{\circ} 10^{\prime}-1^{\circ} 50^{\prime}$ Lintang Utara dan $98^{\circ} 50^{\prime}-100^{\circ} 10^{\prime}$ Bujur Timur.

Berbatasan dengan Kabupaten Tapanuli Selatan pada arah utara, Provinsi Sumatera Barat pada arah timur dan selatan, dan Samudera Hindia pada arah barat. Peta lokasi penelitian dapat dilihat pada Gambar 1. 


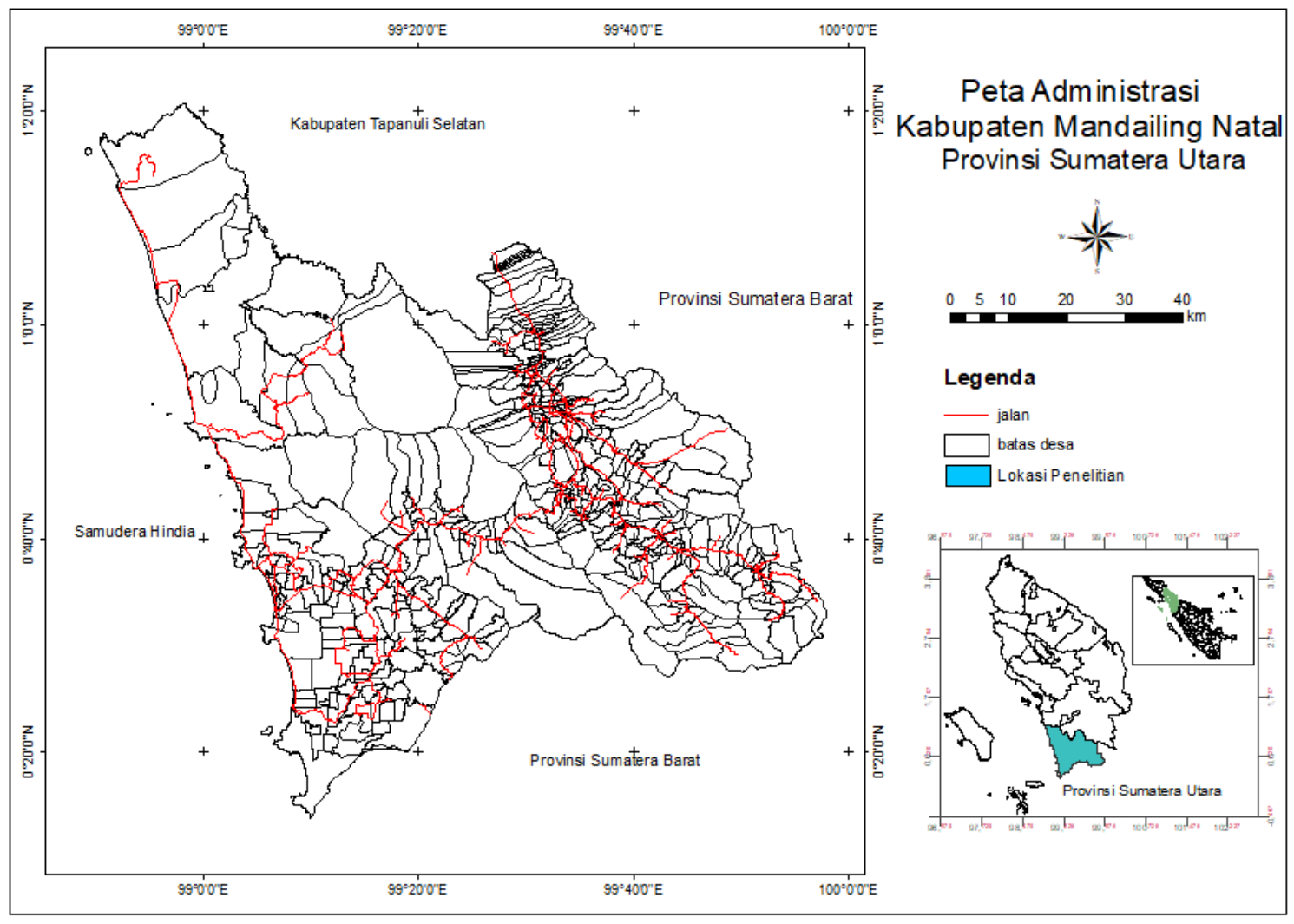

Gambar 1. Peta lokasi penelitian Sumber: BIG, 2019.

\section{Analisis Indikator/Variabel Penciri dan Pengukuran Indeks Pembangunan Berkelanjutan Lokal}

Penentuan indikator pembangunan berkelanjutan di tingkat lokal menggunakan metode Factor Analysis (FA). Analisis faktor yang bersifat eksploratif, dengan tidak membedakan antara variabel independen dan dependen. Dalam analisis ini syarat untuk menjadi faktor baru jika nilai eigen $>1$. Nilai eigen menunjukkan seberapa besar pengaruh suatu variabel terhadap pembentukan karakteristik sebuah matriks. Tahapan selanjutnya adalah menentukan skor faktor dengan menggabungkan beberapa varian dalam satu faktor (summated scale)

Tabel 1. Variabel/indikator pengukuran Indeks Pembangunan Berkelanjutan Lokal

\begin{tabular}{|c|c|c|}
\hline Indikator Ekonomi $(k=1)$ & Indikator Sosial $(k=2)$ & Indikator Lingkungan $(k=3)$ \\
\hline V1: Jarak desa ke pasar (km) & $\begin{array}{l}\text { V8: Jumlah fasilitas pendidikan } \\
\text { (TK-PT) per } 1000 \text { populasi }\end{array}$ & $\begin{array}{l}\text { V15: Persentase luas hutan per } \\
\text { total area }(\%)\end{array}$ \\
\hline V2: Jarak desa ke bank (km) & $\begin{array}{ll}\text { V9: Jumlah fasilitas kesehatan } \\
\text { (RS, Klinik, Pusat } \\
\text { Kesehatan, Dokter per } \\
1000 \text { populasi) }\end{array}$ & $\begin{array}{l}\text { V16: Persentase luas kebun per } \\
\text { total area }(\%)\end{array}$ \\
\hline V3: Jarak desa ke kota $(\mathrm{km})$ & $\begin{array}{l}\text { V10: Jumlah pegawai kesehatan } \\
\text { per } 1000 \text { populasi }\end{array}$ & $\begin{array}{l}\text { V17: Perubahan tutupan lahan } \\
\text { dari sawah ke non pertanian } \\
\text { (ha) }\end{array}$ \\
\hline $\begin{array}{l}\text { V4: Jumlah industri per } 1000 \\
\text { populasi }\end{array}$ & $\begin{array}{l}\text { V11: Jumlah penduduk miskin } \\
\text { dan tidak mampu (jiwa) }\end{array}$ & $\begin{array}{l}\text { V18: Perubahan tutupan lahan } \\
\begin{array}{l}\text { pertanian } \\
\text { pertanian(ha) }\end{array}\end{array}$ \\
\hline $\begin{array}{l}\text { V5: Jumlah Hotel /Motel dan Inn } \\
\text { per } 1000 \text { populasi }\end{array}$ & $\begin{array}{l}\text { V12: Rumah tangga teraliri } \\
\text { listrik }\end{array}$ & $\begin{array}{l}\text { V19: Perubahan tutupan lahan } \\
\text { hutan ke pertanian (ha) }\end{array}$ \\
\hline $\begin{array}{l}\text { V6: Persentase luas } \\
\text { permukiman/total area }\end{array}$ & $\begin{array}{l}\text { V13: Jumlah tower telepon } \\
\text { seluler (BTS) }\end{array}$ & $\begin{array}{l}\text { V20: Perubahan tutupan lahan } \\
\text { hutan ke non pertanian (ha) }\end{array}$ \\
\hline
\end{tabular}




\begin{tabular}{ccc}
\hline Indikator Ekonomi (k= 1) & Indikator Sosial $(\mathbf{k = 2})$ & Indikator Lingkungan $(\mathbf{k}=\mathbf{3})$ \\
\hline $\begin{array}{l}\text { V7: Indeks infrastruktur ekonomi } \\
\text { (skalogram) }\end{array}$ & $\begin{array}{c}\text { V14: Jumlah warga penderita } \\
\text { gizi buruk (jiwa) }\end{array}$ & V21: Jumlah kejadian bencana \\
\hline Sumber: Pravitasari et al (2018) dan dimodifikasi.
\end{tabular}

Sumber: Pravitasari et al. (2018) dan dimodifikasi.

Penentuan Indeks Pembangunan Berkelanjutan Lokal dengan cara mengalkulasikan skor faktor dan nilai eigen faktor baru hasil analisis faktor ke dalam rumus persamaan sebagai berikut (Pravitasari et al., 2018):

$$
\operatorname{IPBL} k i=\sum_{\mathrm{m}=1}^{\mathrm{nk}} \text { Ekm. Skmi. }
$$

\section{Keterangan:}

IPBLki : IPBL untuk dimensi ke-k di desa/kelurahan ke-i;

K : Dimensi, $\mathrm{k}=1$; ekonomi, $\mathrm{k}=2$; sosial, $\mathrm{k}=3$; lingkungan);

Ekm : Nilai eigen untuk dimensi ke-k pada faktor ke-m;

Skmi : Skor faktor untuk dimensi ke-k, faktor ke-m pada kelurahan ke-i;

i $\quad: 1,2,3, \ldots, n$.

Untuk menstandarisasi nilai IPBL menggunakan metode standarisasi maksimum minimum:

$$
\operatorname{IPBL}(\mathrm{std})=\frac{(I P B L k i-I P B L \mathrm{~min})}{\operatorname{IPBLki}(\mathrm{maks})-I P B L k i(\min )} \times 100
$$

\section{Analisis pola spasial Indeks Pembangunan Berkelanjutan Lokal}

Pengukuran Indeks Pembangunan Berkelanjutan di tingkat lokal dicirikan dengan adanya saling ketergantungan lokasi secara lokal, dalam hal ini peneliti menggunakan alat bantu software Geoda. Untuk mengukur autokorelasi secara lokal menggunakan metode Local Indicator of Spatial Autocorrelation (LISA) seperti yang telah dikerjakan Jiao \& Liu (2012), dan Marinda et al. (2020). Semakin tinggi nilai Local Moran Indeks menggambarkan wilayah yang bertetangga memiliki nilai amatan yang semakin sama. Indeks Moran mengukur apakah $\mathrm{x}$ dan y saling berkorelasi dalam satu variabel misal $k i$ dan $k j$, maka persamaan dari
Indeks Moran adalah sebagai berikut (Arlinghaus, 1996);

$$
\begin{gathered}
I=\frac{\sum_{i=1}^{\mathrm{n}} * \sum_{\mathrm{j}=1}^{\mathrm{n}} w i j(\mathrm{xki}-\overline{\mathrm{xk}})(\mathrm{xkj}-\overline{\mathrm{xk}})}{\mathrm{Z}_{\mathrm{xk}}^{2} \sum_{\mathrm{i}=1}^{\mathrm{n}} * \sum_{\mathrm{j}=1}^{\mathrm{n}} w i j} \\
\mathrm{Ii}=\frac{\sum_{\mathrm{j}=1}^{\mathrm{n}} w i j(\mathrm{xki}-\overline{\mathrm{xk}})(\mathrm{xkj}-\overline{\mathrm{xk}})}{\mathrm{Z}_{\mathrm{xk}}^{2} \sum_{\mathrm{j}=1}^{\mathrm{n}} w i j}
\end{gathered}
$$

Keterangan:

I = Global Moran's Index;

Ii = Local Moran's I atau LISA statistics;

$\mathrm{x} k i=$ Nilai IPBL dimensi ke-k pada desa

$$
\text { ke-i; }
$$

$\overline{\mathrm{x}} \mathrm{k}=$ Rata-rata IPBLk;

Wij = Matrix Contiguity;

$\mathrm{n} \quad=$ jumlah desa/kelurahan;

$\mathrm{Z}_{\mathrm{xk}}^{2}=$ varian IPBL $k$.

Matriks pembobot (matrix contiguity) merupakan hubungan ketetanggaan (neighbouring) yang dinyatakan dalam matriks pembobot W. Elemen-elemen matriks tersebut adalah Wij yang menunjukkan ukuran hubungan lokasi ke-i dan ke-j. Matriks pembobot spasial dalam penelitian ini berukuran $404 \times 404$ yang merupakan jumlah desa/kelurahan di Kabupaten Mandailing Natal. Pembobotan matriks yang digunakan adalah rook contiguity. Menurut Kosfeld \& Dreger (2006), hubungan ketetanggaan rook contiguity adalah pembobot matrik yang berdasarkan sisi-sisi yang saling bersinggungan dan bagian sudutnya tidak diperhitungkan. Ilustrasi rook contiguity disajikan pada gambar 2, unit B1, B2, B3 dan B4 merupakan tetangga unit $\mathrm{A}$.

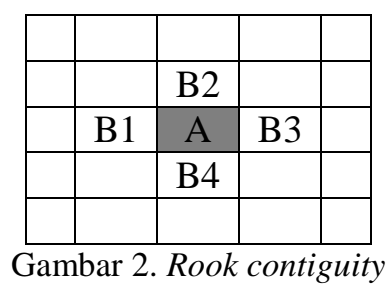

Nilai Indeks Moran berkisar antara -1 sampai 1 , jika nilai $\mathrm{I}<0$ berarti terdapat 
autokorelasi spasial negatif, dan jika nilai I > 1 berarti terdapat autokorelasi spasial positif.

\section{HASIL DAN PEMBAHASAN}

\section{Indikator/Variabel Penciri Indeks Pembangunan Berkelanjutan Lokal}

Hasil analisis pemilihan indikator ekonomi pada tahun 2011 dan 2018 ditampilkan pada Tabel 1, variabel yang digunakan berjumlah 7 variabel. Faktor baru yang dihasilkan jumlahnya berbeda di dua titik tahun ini. Pada tahun 2011 terbentuk 3 faktor baru sedangkan tahun 2018 hanya terbentuk 2 faktor. v4 dan v5 tidak menjadi indikator penciri pada tahun 2018. Variabel v1, v2, v3, v7 merupakan indikator penciri yang sama pada dua titik tahun. Indikator tersebut merupakan akses menuju aktivitas perekonomian dan indeks infrastruktur.
Penentuan jumlah faktor dilihat dari nilai spesifik dari persentase kumulatif keragaman yang bisa dijelaskan oleh faktor yang terbentuk. Syarat untuk menjadi faktor baru apabila eigenvalue yang dihasilkan $>1$. Faktor pertama akan mengekstrak varian yang paling umum terlebih dahulu kemudian faktor berikutnya mengekstrak varian lainnya secara berurutan dan porsinya akan lebih kecil. Proses ini akan menghasilkan eigenvalue yang menurun secara berurutan. Hasil analisis menunjukkan nilai eigen faktor 1 selalu lebih besar dibanding nilai eigen faktor 2 , faktor 3 dan seterusnya. Sejalan dengan penelitian Mahmood \& Ahmed (2014), semakin besar nilai eigen semakin representatif faktor baru tersebut mewakili semua matriks data.

Tabel 2. Faktor loading indikator ekonomi tahun 2011 dan 2018

\begin{tabular}{crrrrr}
\hline \multirow{2}{*}{ Variabel } & \multicolumn{3}{c}{$\mathbf{2 0 1 1}$} & \multicolumn{2}{c}{$\mathbf{2 0 1 8}$} \\
\cline { 2 - 6 } & Faktor 1 & Faktor 2 & Faktor 3 & Faktor 1 & Faktor 2 \\
\hline V1 & $\mathbf{- 0 . 8 3}$ & 0.03 & -0.05 & $\mathbf{- 0 . 7 5}$ & 0.04 \\
V2 & $\mathbf{- 0 . 8 4}$ & 0.02 & -0.08 & $\mathbf{- 0 . 8 1}$ & -0.09 \\
V3 & 0.65 & 0.18 & 0.14 & $\mathbf{- 0 . 8 4}$ & -0.01 \\
V4 & 0.08 & $\mathbf{0 . 8 8}$ & -0.11 & 0.03 & 0.68 \\
V5 & -0.05 & 0.09 & $\mathbf{0 . 8 0}$ & -0.03 & 0.53 \\
V6 & 0.24 & 0.07 & 0.40 & 0.10 & 0.62 \\
V7 & 0.02 & $\mathbf{0 . 7 6}$ & 0.35 & 0.12 & $\mathbf{0 . 8 0}$ \\
\hline Eigenvalue & 2.21 & 1.44 & 1.09 & 2.33 & 1.61 \\
\hline \% Total variance & 27.67 & 17.95 & 13.68 & 29.24 & 20.17 \\
\hline Cumulative eigenvalue & 27.67 & 45.63 & 59.31 & 29.24 & 49.42 \\
\hline
\end{tabular}

Sumber: Hasil analisis data (2021).

Nilai eigen dihitung untuk masing-masing faktor yang dihasilkan untuk menunjukkan jumlah variasi data. Nilai kumulatif eigenvalue yang membentuk faktor baru dimensi ekonomi adalah 59.31 pada tahun 2011 dan 49.42 pada tahun 2018 (Tabel 2). Faktor-faktor laten ini dapat menjelaskan variabel yang diwakilinya sebesar 59\% varian kumpulan data pada tahun 2011 dan 49\% pada tahun 2018.

Variabel yang memiliki nilai loading faktor > 0.7 merupakan indikator penciri. Ada beberapa hal yang mempengaruhi nilai loading faktor suatu variabel, yaitu koefisien korelasi variabel tersebut dan variasi data yang ada dalam indikator. Variasi data yang tinggi akan berpotensi kuat untuk memiliki loading faktor yang tinggi. Indikator dengan faktor loading rendah memiliki kontribusi lemah untuk menjelaskan konstruk latennya. Sehingga indikator penciri dalam penelitian ini terdapat perbedaan untuk tiap tahunnya.

Variabel dimensi sosial yang diringkas berjumlah 7 variabel (Tabel 3), jumlah fasilitas kesehatan, jumlah pegawai kesehatan, jumlah rumah tangga teraliri listrik dan jumlah warga penderita gizi buruk merupakan indikator penciri yang sama di tahun 2011 dan 2018 karena variabel tersebut memiliki nilai faktor loading $>0.7$. Indikator ini merupakan indikator yang sangat berhubungan langsung dengan 
peningkatan kualitas hidup manusia. Namun di tahun 2011 terdapat variabel penciri yang berbeda yaitu; jumlah fasilitas pendidikan (v8), karena di tahun 2018 nilai faktor loading variabel ini $<0.7$ sehingga kontribusinya belum terlalu kuat untuk menjelaskan konstruk latennya. Nilai eigen kumulatif indikator sosial ini lebih tinggi jika dibandingkan dengan dimensi ekonomi. Nilai cumulative eigenvalue tahun 2011 dan 2018 adalah 66.67 dan 59.32 yang berarti faktor tersebut cukup tinggi dapat menjelaskan matriks datanya.

Tabel 3. Faktor loading indikator sosial tahun 2011 dan 2018

\begin{tabular}{ccccc}
\hline Variabel & \multicolumn{2}{c}{$\mathbf{2 0 1 1}$} & \multicolumn{2}{c}{$\mathbf{2 0 1 8}$} \\
\cline { 2 - 5 } & Faktor 1 & Faktor 2 & Faktor 1 & Faktor 2 \\
\hline v8 & $\mathbf{0 . 8 5}$ & 0.44 & 0.60 & 0.39 \\
v9 & $\mathbf{0 . 7 1}$ & -0.17 & $\mathbf{0 . 7 8}$ & 0.02 \\
v10 & $\mathbf{0 . 8 7}$ & 0.07 & $\mathbf{0 . 8 3}$ & 0.04 \\
v11 & 0.58 & 0.59 & 0.56 & 0.02 \\
v12 & 0.89 & 0.16 & $\mathbf{0 . 8 4}$ & 0.13 \\
v13 & 0.48 & -0.23 & 0.58 & 0.01 \\
v14 & -0.12 & $\mathbf{0 . 7 6}$ & -0.01 & $\mathbf{0 . 9 6}$ \\
\hline Eigenvalue & 3.57 & 1.09 & 3.12 & 1.02 \\
\hline \% Cotal variance & 51.03 & 15.63 & 44.66 & 14.65 \\
\hline
\end{tabular}

Sumber: Hasil analisis data (2021).

Tabel 4. Faktor loading indikator lingkungan tahun 2011 dan 2018

\begin{tabular}{crrrrrr}
\hline Variabel & \multicolumn{3}{c}{$\mathbf{2 0 1 1}$} & \multicolumn{3}{c}{$\mathbf{2 0 1 8}$} \\
\cline { 2 - 7 } & Faktor 1 & Faktor 2 & Faktor 3 & Faktor 1 & Faktor 2 & Faktor 3 \\
\hline v15 & 0.14 & $\mathbf{- 0 . 8 5}$ & -0.06 & 0.03 & 0.09 & 0.62 \\
v16 & -0.01 & $\mathbf{0 . 8 7}$ & -0.06 & -0.03 & -0.69 & -0.20 \\
v17 & -0.09 & 0.15 & $\mathbf{- 0 . 9 1}$ & 0.02 & $\mathbf{- 0 . 7 7}$ & 0.14 \\
v18 & 0.45 & -0.01 & $\mathbf{- 0 . 7 9}$ & $\mathbf{0 . 7 5}$ & -0.11 & 0.06 \\
v19 & $\mathbf{0 . 8 7}$ & -0.11 & 0.01 & $\mathbf{0 . 8 5}$ & 0.09 & 0.01 \\
v20 & $\mathbf{0 . 8 8}$ & -0.03 & 0.01 & $\mathbf{0 . 8 6}$ & 0.04 & -0.09 \\
v21 & 0.14 & 0.15 & 0.26 & 0.04 & 0.06 & $\mathbf{- 0 . 7 7}$ \\
\hline Eigenvalue & 1.99 & 1.64 & 1.24 & 2.04 & 1.13 & 1.05 \\
\hline \%otal variance & 27.67 & 17.95 & 13.68 & 29.14 & 16.09 & 14.94 \\
\hline Cumulative eigenvalue & 27.67 & 51.93 & 69.65 & 29.14 & 45.24 & 60.19 \\
\hline Suyyyyyy
\end{tabular}

Sumber: Hasil analisis data (2021).

Tabel 4 menyajikan nilai faktor loading variabel penciri indikator lingkungan pada tahun 2011 dan 2018. Pada dua titik tahun sama-sama terbentuk 3 faktor konstruk. Jika dibandingkan terdapat 2 variabel yang berbeda, yaitu luas tutupan lahan hutan (v15) dan luas tutupan lahan kebun (v16), ini disebabkan nilai korelasinya yang cukup rendah pada tahun 2018. Nilai korelasi dua variabel ini cukup tinggi pada tahun 2011 (-0.53) namun pada tahun 2018 korelasi keduanya terhadap semua indikator bernilai $<0.07$. Indikator perubahan tutupan lahan dari sawah ke non pertanian, perubahan tutupan lahan pertanian ke non pertanian, perubahan tutupan lahan hutan ke non pertanian merupakan indikator penciri yang sama pada dua titik tahun. Berdasarkan nilai faktor loadingnya, kejadian bencana (v21) menjadi variabel penciri pada tahun 2018 namun pada tahun 2011 faktor loadingnya cukup rendah. Faktor baru ini paling representatif karena kemampuannya menjelaskan matriks data paling tinggi (69.65; 60.19) dibandingkan dengan faktor baru pada dimensi ekonomi dan sosial. 
Indeks Pembangunan Berkelanjutan Lokal (IPBL)

Pengukuran IPBL yang dilakukan secara parsial dapat mengidentifikasi tingkat pembangunan berkelanjutan pada masingmasing dimensi pembangunan sehingga lebih mudah menentukan fokus pembangunan dan arahan kebijakan pembangunannya. Hasil persamaan IPBL distandarisasi terlebih dahulu, karena beberapa variabel memiliki satuan dan range angka yang berbeda. Tujuan standarisasi indeks adalah untuk mempersempit perbedaan satuan dan perbedaan nilai yang tinggi, sehingga nilai indeksnya menjadi nilai baku.

Hasil pengukuran IPBL pada tiap dimensi ekonomi, sosial, dan lingkungan di Kabupaten Mandailing Natal dibagi kedalam tiga kategori, yaitu rendah (0.00-30.00) berwarna merah; sedang (30.01-70.00) berwarna kuning; dan tinggi (70.01-100.00) warna hijau. Secara total wilayah tingkat keberlanjutan ekonomi di daerah ini berkategori sedang (95.54\%), keberlanjutan sosial dan lingkungan rendah $(88.86 \% ; 92.82 \%)$. Jumlah desa berkategori tinggi nilai indeks IPBL1, 2 dan 3 berturut turut yaitu 56 (13\%), 21 (5\%), $10(2 \%)$ pada tahun 2018.

Pertambahan jumlah desa berkategori tinggi IPBL ekonomi yang sedikit menunjukkan tidak terdapat banyak perbedaan dalam kurun waktu 7 tahun. Hal ini mengindikasikan peningkatan keberlanjutan pembangunan dimensi ekonomi dan dimensi sosial tidak terlalu signifikan. Berdasarkan nilai IPBL ekonomi yang secara umum berkategori sedang, menunjukkan jarak desa ke pasar, jarak desa ke bank dan jarak desa ke kota di tiap-tiap desa masih dalam rentang yang sedang.

Demikian halnya dengan IPBL sosial, dengan mengamati pertambahan jumlah desa (36 desa) berindeks IPBL sosial berkategori sedang, peningkatan aksesibilitas terhadap fasilitas kesehatan, kebutuhan energi (akses terhadap listrik) dan peningkatan status kesehatan belum terlalu signifikan di wilayah ini. Hal ini mengindikasikan bahwa secara umum pemenuhan kebutuhan dasar di Kabupaten Mandailing Natal masih rendah. Akses terhadap kesehatan dan pemenuhan kebutuhan energi merupakan hal yang harus menjadi fokus pembangunan dalam peningkatan pencapaian pembangunan berkelanjutan.

Pada tahun 2018 tingkat pembangunan berkelanjutan dimensi lingkungan menurun, sebesar $92.82 \%$ desa dengan nilai IPBL lingkungan berkategori rendah. Penyebabnya bisa diamati dari variabel pencirinya, yaitu perubahan tutupan lahan dari pertanian ke non pertanian, dan perubahan tutupan lahan hutan yang tinggi. Ini berkaitan dengan struktur perekonomian wilayah ini masih berstruktur primer. Dengan memanfaatkan sumber daya alam (pertanian, pertambangan, penggalian) dalam memenuhi kebutuhannya. Kebutuhan ruang untuk aktivitas ekonomi mengakibatkan lahan yang dianggap lebih rendah nilai ekonominya dialihkan ke penggunaan lain. Misalnya lahan hutan berubah menjadi perkebunan campuran atau perkebunan sawit. Lahan sawah berubah penggunaannya untuk perkebunan campuran, permukiman, ataupun lahan terbuka. Jika tetap dibiarkan akan mengakibatkan pembangunan berkelanjutan sulit tercapai. Sejalan dengan hasil studi Fauzi \& Oktavianus (2014), pembangunan ekonomi cenderung akan mengorbankan lingkungan jika pelaksanaan pembangunan tidak sebanding antar dimensinya.

Pada wilayah ini belum ada desa dengan tingkat pembangunan berkelanjutannya berkategori tinggi pada tiga dimensi pembangunan. Kelurahan Panyabungan II merupakan wilayah dengan kategori paling tinggi tingkat keberlanjutan ekonomi dan sosialnya, tetapi tingkat keberlanjutan pembangunan lingkungannya dalam kategori sedang. Ataupun sebaliknya, Hutaimbaru masuk dalam kategori tinggi pada dimensi lingkungan namun tingkat keberlanjutan ekonomi dan sosial berkategori rendah. Dari indikator pencirinya dapat diamati bahwa kondisi ini disebabkan oleh terbatasnya akses jalur transportasi yang menjadi faktor penghambat pembangunan ekonomi desa Hutaimbaru, dan intensitas perubahan tutupan lahan yang tinggi pada Kelurahan Panyabungan II. 


\section{Sebaran Spasial Indeks Pembangunan Berkelanjutan Lokal}

Sebaran nilai Indeks Pembangunan Berkelanjutan lokal dapat diamati pada gambar 2, terjadi peningkatan keberlanjutan pembangunan ekonomi berkategori rendah menjadi kategori sedang di arah timur. Wilayah yang mengalami peningkatan ini letaknya berdekatan dengan jalur transportasi, pusat perdagangan, dan pusat pemerintahan. Senada dengan yang disampaikan Yudha et al. (2020) wilayah dapat lebih maju karena banyaknya tarikan kegiatan ekonomi di wilayah tersebut. Selain itu wilayah-wilayah ini merupakan ibukota kecamatan maupun ibukota kabupaten, hirarki sebaran spasialnya mirip dengan hirarki wilayah administratif, sejalan dengan penelitian Jiao \& Liu (2012). Wilayah dengan nilai IPBL ekonomi dan IPBL sosial berkategori tinggi terdapat aktivitas perkebunan, pertambangan maupun perdagangan.

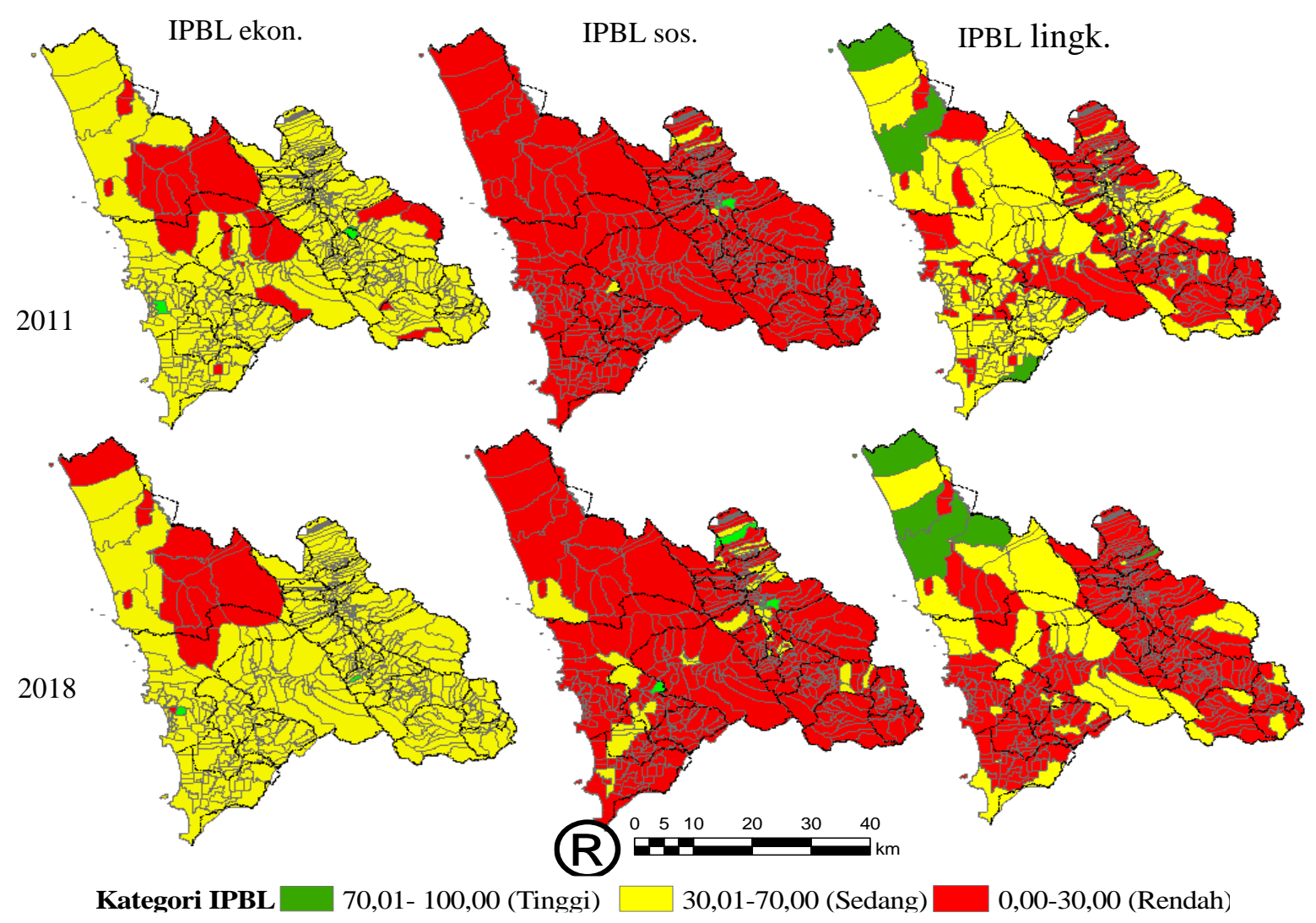

Gambar 3. Sebaran nilai Indeks Pembangunan Berkelanjutan Lokal dimensi ekonomi (IPBLekon), IPBL dimensi sosial (IPBLsos), IPBL dimensi lingkungan (IPBLlingk)

Sumber: Hasil analisis data (2021).

\begin{abstract}
Pengukuran data secara spasial merupakan kekhasan dalam indeks pembangunan keberlanjutan lokal ini. Tahapan selanjutnya adalah nilai IPBL diukur untuk melihat informasi spasialnya, dengan cara melihat hubungan ketetanggaannya. Yaitu hubungan yang mencerminkan lokasi relatif dari satu lokasi amatan ke lokasi pengamatan lainnya. Hasil analisis menunjukkan, informasi nilai indeks moran's nilai IPBL pada tiga
\end{abstract}

dimensi pembangunan adalah 0.44 ; 0.23 ; dan 0.30, terdapat autokorelasi spasial positif. sehingga dapat diinterpretasikan di Kabupaten Mandailing terdapat kesamaan tingkat pembangunan berkelanjutan antar desa yang berdekatan dan pola spasialnya cenderung mengelompok.

Tipe cluster yang dihasilkan dalam autocorrelation spatial ada 4 tipe (Zhukov, 2010) yaitu; High-high (HH) dan Low-low (LL) 
yang bentuk cluster spasialnya mengelompok (hotspot). High-low (HL) dan Low-high (LH) disebut juga outlier spatial atau letaknya individual. Tabel 5 menyajikan perbandingan persentase tipe cluster LISA di tahun 2011 dan 2018. Meskipun nilai IPBL pada tiap dimensi nilai indeks morannya berkorelasi positif dan signifikan, namun di tingkat lokal lebih dari $77 \%$ tidak memiliki tipe cluster spasial yang significant. Selang tahun 2011 dan 2018 tipe cluster spasial yang signifikan paling tinggi adalah dimensi lingkungan sebesar $22.33 \%$ dan dimensi sosial sebesar $16.63 \%$. Secara umum terjadi penurunan pola spasial $\mathrm{HH}$ di semua dimensi, kondisi ini tidak sepenuhnya menandakan tingkat keberlanjutan pembangunan yang menurun, karena di sisi lain wilayah dengan tipe cluster LL dimensi ekonomi dan lingkungan jumlahnya berkurang. Tipe cluster LL mengandung arti daerah amatan dengan nilai IPBL ekonomi dan lingkungan rendah dikelilingi oleh daerah dengan nilai IPBL rendah juga. Sejalan dengan hasil studi Huo et al. (2011); Jiao \& Liu (2012); dan Fauzi et al. (2019) bahwa selain hotspot LL, outlier HL juga perlu diperhatikan pembangunannya agar tidak memberi pengaruh negatif terhadap tingkat keberlanjutan pembangunan wilayah tetangganya. Pada tahun 2018, tipe cluster paling tinggi adalah tipe cluster LL pada dimensi sosial dan dimensi lingkungan. Untuk peningkatan pembangunan berkelanjutan, kedua dimensi ini harus menjadi perhatian juga, peningkatan positif dimensi ekonomi tidak harus mengorbankan dimensi pembangunan lainnya.

Tabel 5. Persentase tipe cluster Indeks Pembangunan Berkelanjutan Lokal di Kabupaten Mandailing Natal

\begin{tabular}{lrrrrrr}
\hline \multirow{2}{*}{ Tipe autokorelasi spasial } & \multicolumn{3}{c}{$\mathbf{2 0 1 1}$} & \multicolumn{3}{c}{$\mathbf{2 0 1 8}$} \\
\cline { 2 - 7 } & \multicolumn{1}{c}{ IPBL1 } & \multicolumn{1}{c}{ IPBL2 } & \multicolumn{1}{c}{ IPBL3 } & IPBL1 & \multicolumn{1}{c}{ IPBL2 } & IPBL3 \\
\hline Not significant & 78.91 & 84.12 & 77.67 & 86.10 & 83.37 & 84.86 \\
High-high & 10.92 & 5.21 & 6.70 & 6.95 & 4.96 & 4.22 \\
Low-low & 8.68 & 7.20 & 11.66 & 5.71 & 7.69 & 7.94 \\
Low-high & 0.74 & 2.73 & 2.23 & 0.74 & 2.73 & 1.99 \\
High-low & 0.74 & 0.74 & 1.74 & 0.50 & 1.24 & 0.99 \\
\hline
\end{tabular}

Sumber: Hasil analisis data (2021)

Gambar 4 menyajikan sebaran pola spasial Indeks Pembangunan Berkelanjutan lokal pada masing-masing dimensi pembangunan. Pada arah timur mengumpul indeks ekonomi dengan tipe cluster HH. Dapat dipahami karena wilayah ini terletak ibukota kabupaten, pusat perdagangan dan merupakan pertemuan beberapa jalur transportasi darat. Tipe spasial LL dimensi ekonomi terletak pada arah barat laut menuju ke arah selatan (Kecamatan Muara Batang Gadis dan Kecamatan Natal). Dalam kurun waktu 7 tahun tidak terlihat perkembangan yang positif pada pembangunan dimensi sosial, justru terjadi peningkatan hotspot LL pada arah selatan (Kecamatan Ulu Pungkut dan Kecamatan Pakantan). Wilayah dengan tingkat keberlanjutan pembangunan sosial yang rendah dipengaruhi oleh tetangganya dengan tingkat keberlanjutan yang sama. Peningkatan fasilitas sosial harus diupayakan agar akses dan proporsinya terhadap jumlah penduduk sebanding sehingga tercapai keseimbangan dengan dimensi keberlanjutan lainnya.

Tipe cluster $\mathrm{HH}$ indeks lingkungan terletak pada arah barat laut dan bergerak ke arah selatan yang merupakan pusat perkebunan. Kondisi ini dapat diinterpretasikan bahwa desa dengan indeks keberlanjutan lingkungan tinggi dikelilingi oleh desa dengan tingkat keberlanjutan lingkungan yang tinggi pula. Sebagaimana disebutkan sebelumnya bahwa tipe spasial IPBL dimensi ekonomi di wilayah ini adalah LL. Tahun 2011 di arah barat lokasi penelitian, pola spasial IPBL lingkungan bertipe HH tetapi pada tahun 2018 desa-desa tersebut dengan tetangganya tidak saling mempengaruhi lagi. Ini dapat diamati melalui tipe autokorelasi spasialnya yang tidak signifikan lagi. Wilayah barat laut (Kecamatan Muara Batang Gadis; 
Kecamatan Natal) dan barat (Kecamatan Batahan; Kecamatan Sinunukan) merupakan zona khusus perkebunan sawit. Sebagian besar penduduk wilayah barat memperoleh manfaat ekonomi dari aktivitas ini. Khususnya penduduk yang memiliki kebun plasma ataupun non plasma, kesejahteraannya cenderung meningkat. Sebagaimana dinyatakan oleh Suryadi et al. (2020) perkebunan kelapa sawit dapat berpengaruh positif dan negatif pada aspek lingkungan, sosial, dan ekonomi komunitas lokal.

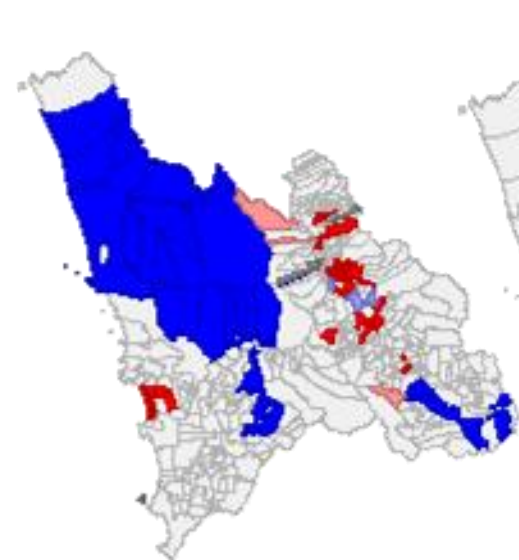

IPBL Ekonomi 2011

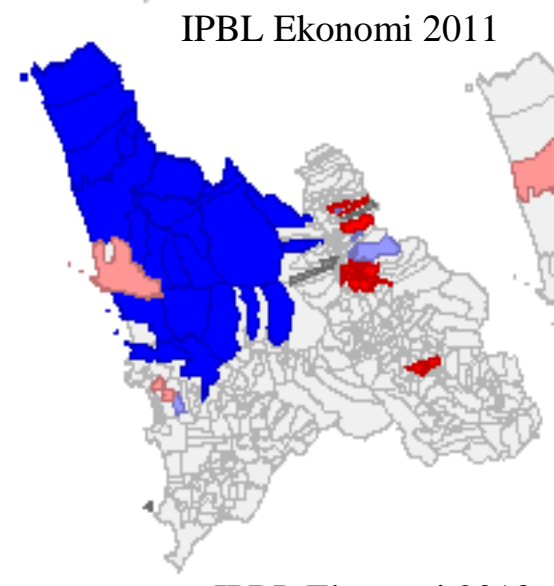

IPBL Ekonomi 2018

\section{LISA map cluster}

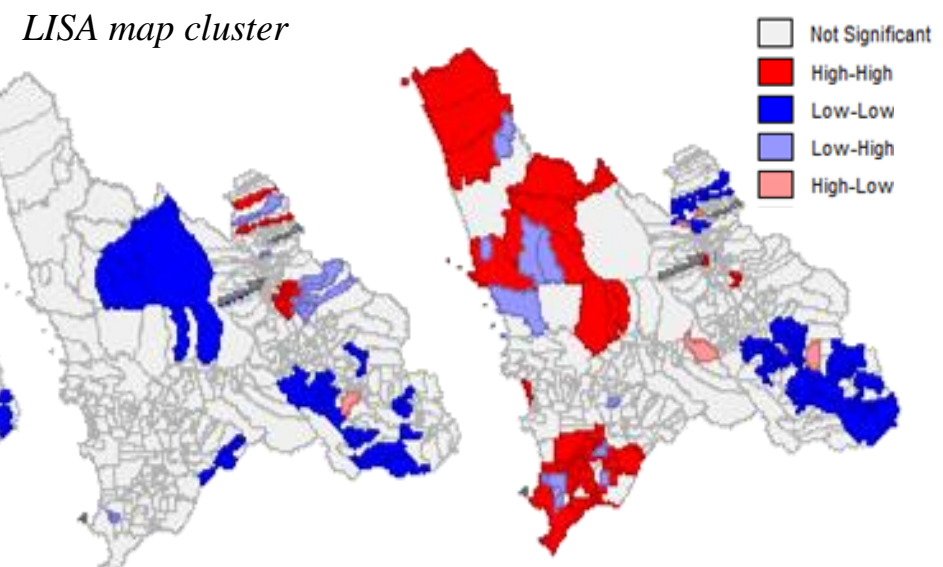

IPBL Sosial 2011
IPBL lingkungan 2011
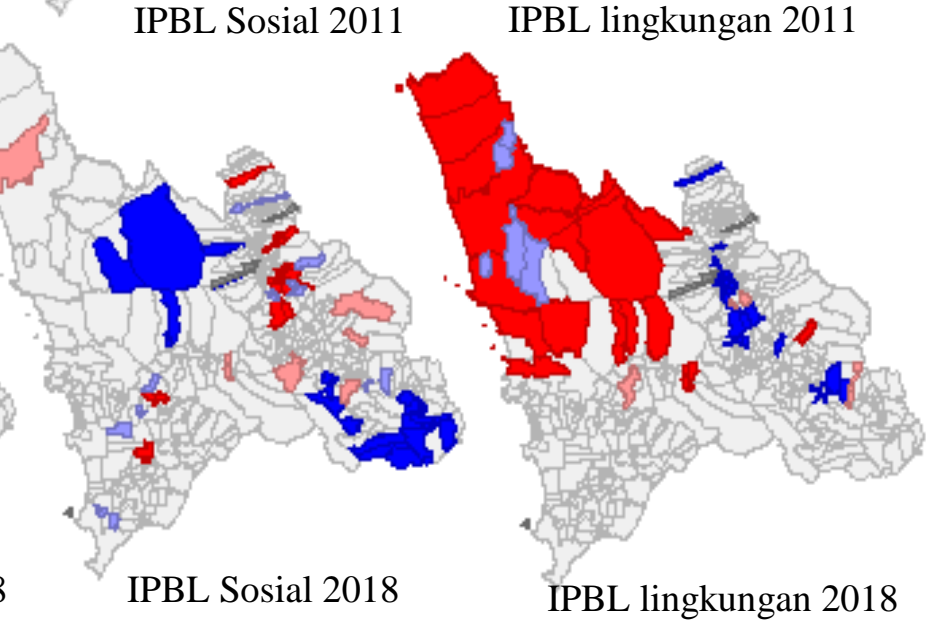

Gambar 4. Sebaran pola spasial IPBL ekonomi, IPBL sosial, dan IPBL lingkungan tahun 2011 dan 2018 Sumber: Hasil analisis (2021).

\section{KESIMPULAN}

Variabel ekonomi, sosial dan lingkungan direduksi menggunakan metode Faktor Analisis (FA), yang menghasilkan variabel yang jumlahnya lebih sedikit namun tetap dapat menggambarkan kondisi sebenarnya. Pengukuran IPBL dilakukan secara parsial sehingga dapat mengidentifikasi tingkat keberlanjutan pembangunan dimensi ekonomi, dimensi sosial dan dimensi lingkungan dalam suatu wilayah.
Nilai indeks ini bisa mengukur tingkat pembangunan berkelanjutan pada tingkat lokal. Secara umum tingkat keberlanjutan pembangunan ekonomi wilayah berkategori sedang, keberlanjutan sosial dan keberlanjutan lingkungan berkategori rendah. Hasil analisis menunjukkan nilai indeks moran global bernilai positif berarti terdapat kesamaan antar desa/kelurahan yang diamati dan cenderung mengelompok. Pola spasial HH dan LL dinamis di kedua titik tahun. Terjadi aksi timbal balik, jika pola indeks ekonomi bertipe spasial $\mathrm{HH}$ meningkat maka tipe spasial indeks lingkungan 
LL meningkat juga. Ini akibat internalisasi dampak lingkungan dalam kegiatan ekonomi masih cenderung terabaikan. cluster spasial IPBL dimensi ekonomi dan dimensi sosial $\mathrm{HH}$ umumnya tersebar pada arah timur, sebaran cluster IPBL3 tipe cluster $\mathrm{HH}$ tersebar pada arah barat laut. Indeks ini bisa menjadi bahan pertimbangan untuk meningkatkan pembangunan berkelanjutan baik dari dimensinya maupun dari sebaran spasialnya.

\section{UCAPAN TERIMAKASIH}

Terima Kasih penulis ucapkan kepada Pusat Pembinaan, Pendidikan, dan Pelatihan Perencana Badan Perencanaan Pembangunan Nasional (Pusbindiklatren Bappenas) yang telah memberi beasiswa, BPS, dan United Stated Geological Survey (USGS) yang memberikan kemudahan akses data sehingga penelitian ini dapat terlaksana.

\section{DAFTAR PUSTAKA}

Arlinghaus, S. L. (1996). Practical Handbook of Spatial Statistics. CRC Press Inc

Atifah, Y. \& Harahap, F. S. (2019). Effect of Heavy Metal Spread on River Flows from Gold Mining Toward Water Biota in Batang Gadis Mandailing Natal River. Budapest Int. Res. Exact Sci. J, 2(1), 37-43. doi:10.33258/birex.v2i1.222.

[Bappeda] Badan Perencanaan Pembangunan Daerah . (2018). Strategi Sanitasi Kabupaten Mandailing Natal. Panyabungan: Pemda Kab. Mandailing Natal

[BPS] Badan Pusat Statistik. (2020). Kabupaten Mandailing Natal dalam Angka 2020. Panyabungan: BPS

Fadli, C. N. (2017). Sustainable Landscape for a Livable Village in Mandailing. Fourth International Conference on Sustainable Built Environment. 549-559. Yogyakarta.

Fauzi, A., \& Oxtavianus, A. (2014). Pengukuran Pembangunan Berkelanjutan di Indonesia. MIMBAR, Jurnal Sosial dan Pembangunan, 30(1), 42-52. https://doi.org/10.29313/mimbar.v30i1.445.
Fauzi, M. R., Rustiadi, E., \& Mulatsih, S. (2019). Ketimpangan, Pola Spasial, dan Kinerja Pembangunan Wilayah di Provinsi Jawa Timur. Journal of Regional and Rural Development Planning (Jurnal Perencanaan Pembangunan Wilayah Dan Perdesaan), 3(3), 157-171. https://doi.org/10.29244/jp2wd.2019.3.3.157171

Huo, X. N., Zhang, W. W., Sun, D. F., Li, H., Zhou, L. D., \& Li, B. G. (2011). Spatial pattern analysis of heavy metals in Beijing agricultural soils based on Spatial Autocorrelation Statistics. Int J Environ Res Public Health, 8(6), 2074-89. doi: 10.3390/ijerph8062074.

Jiao, L., \& Liu, Y. (2012). Analyzing the Spatial Autocorrelation of Regional Urban Datum Land Price. Geo-spatial Information Science, 15(4), 263-269. doi: 10.1080/10095020.2012.714103.

Kosfeld, R. \& Dreger, C. (2006). Threshold for employment and unemployment: A Spatial Analysis of German Regional Labour Markets, 1992-2000. Paper in Regional Science, 85(4), 523-542.

Mahmood, K. \& Ahmed, R. (2014). Regional Diversity and Development between the Southern Provinces of Pakistan : A Principal Component Analysis. Human GeographiesJournal of Studies and Research in Human Geography, 8(1), 17-26.

Marinda, R., Sitorus, R. P. S., \& Pribadi, D. O. (2020). Analisis Pola Spasial Persebaran Kawasan Lahan Pertanian Pangan Berkelanjutan di Kabupaten Karawang. Jurnal Geografi, 12(2), 161-173. doi: 10.24114/jg. v12i02.17646.

Pravitasari, A. E., Rustiadi, E., Mulya, S. P., \& Fuadina, L. N. (2018). Developing Regional Sustainability Index as a New Approach for Evaluating Sustainability Performance in Indonesia. Environ. Ecol. Res, 6(3), 157-168. doi:10.13189/eer.2018.060303.

Pravitasari, A. E., Rustiadi, E., Singer, J., \& Fuadina, L. N. (2018). Developing Local Sustainability Index (LSI) at Village Level in Jambi Province. Dalam Suratman, M. Baiquni, S. Hasanati (editor). Innovation of Rural Development for Implementing Sustainable Development Goals, The $8^{\text {th }}$ Rural Research and Planning Group International Conferences, 16-17. Yogyakarta 
Rahma, H., Fauzi, A., Juanda, B., \& Widjojanto, B. (2019). Development of a Composite Measure of Regional Sustainable Development in Indonesia. Sustainability, 11(20), 1-16. (in Switzerland) https://doi.org/10.3390/su11205861

Rustiadi, E., Saefulhakim, S., \& Panuju, D. R. (2009). Perencanaan dan Pengembangan Wilayah. Yayasan Pustaka Obor.

Saric, R., Jelocnik, M., \& Popovic, V. (2013). The Indexing Approach in Measuring of Sustainable Society. Economics of Agriculture, 60(1), 77-90. (in Serbia)

Setianingtias, R., Baiquni, M., \& Kurniawan, A. (2019). Pemodelan Indikator Tujuan Pembangunan Berkelanjutan Di Indonesia. Jurnal Ekonomi Dan Pembangunan, 27(1), 61-74.

Sihombing, B. H., \& Sumaryono, M. (2009). Analisis Kawasan dan Perubahan Penutupan Lahan Taman Nasional Batang Gadis, Kabupaten Mandailing Natal Sumatera Utara. J. Kehutanan Tropika Humida, 2 (1), 12-28.

Suryadi, S., Dharmawan, A. H., \& Barus, B. (2020). Ekspansi Perkebunan Kelapa Sawit: Persoalan Sosial, Ekonomi dan Lingkungan Hidup (Studi Kasus Kab. Pelalawan, Riau). Jurnal Ilmu Lingkungan, 18(2), 367-374. https://doi.org/10.14710/jil.18.2.367-374

Yudha, E. P., Juanda, B., Kolopaking, L.M., \& Kinseng, R. A. (2020). Rural Development Policy and Strategy in the Rural Autonomy Era. Case Study of Pandeglang RegencyIndonesia. Human Geographies- Journal of Studies and Research in Human Geography, 14(1), 125-147.

Zhukov, Y. (2010). Spatial Autocorrelation. Harvard University, IQQS. 